\title{
Sưstailnable Chemistry\& Engineering

\section{Full, Reactive Solubilization of Humin Byproducts by Alkaline Treatment and Characterization of the Alkali-Treated Humins Formed}

\author{
Ilona van Zandvoort, ${ }^{\dagger}$ Ernst R. H. van Eck, ${ }^{\ddagger}$ Peter de Peinder, ${ }^{\S}$ Hero J. Heeres, ${ }^{\perp}$ Pieter C. A. Bruijnincx, ${ }^{*}{ }^{\dagger}$ \\ and Bert M. Weckhuysen*, ${ }^{\dagger}$ \\ ${ }^{\dagger}$ Inorganic Chemistry and Catalysis, Debye Institute for Nanomaterials Science, Utrecht University, Universiteitsweg 99,3584 CG \\ Utrecht, The Netherlands \\ ${ }^{\ddagger}$ Institute for Molecules and Materials, Radboud University, Heyendaalseweg 135, 6525 AJ Nijmegen, The Netherlands \\ ${ }^{\S}$ VibSpec, Haaftenlaan 28, 4006 XL Tiel, The Netherlands \\ ${ }^{\perp}$ Green Chemical Reaction Engineering, University of Groningen, Nijenborgh 4, 9747 AG Groningen, The Netherlands
}

ABSTRACT: The valorization of the humin byproducts that are formed during hydrothermal, acid-catalyzed dehydration of carbohydrates is hampered by the insolubility of these byproducts. Here, we report on an alkaline pretreatment method that allows for the insolubility of this highly recalcitrant and structurally complex feed to be overcome. The reactive solubilization of glucose-derived humins was found to require a treatment at $200{ }^{\circ} \mathrm{C}$ in $0.5 \mathrm{M} \mathrm{NaOH}$ for 3.5 h. Fructose- and xylose-derived humins were found to be more recalcitrant, and complete dissolution required raising the temperature to $240{ }^{\circ} \mathrm{C}$. Gel permeation chromatographic
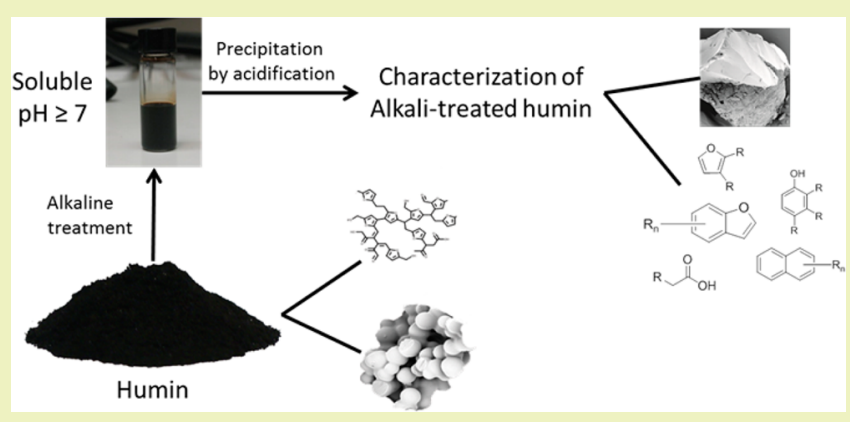
analyses show the relative average molecular weight of the now soluble humins to decrease with increasing temperature and reaction time. The alkali-treated humins are soluble in water of $\mathrm{pH}$ $\geq 7$. Elemental analysis, IR, 2D PASS ${ }^{13} \mathrm{C}$ solid-state NMR and pyrolysis-GC-MS (gas chromatography-mass spectrometry) data indicate that the alkaline pretreatment leads to considerable changes in the molecular structure of the humins. Cleavage of $\mathrm{C}-\mathrm{O}-\mathrm{C}$ bonds and further aromatization of the originally highly furanic humins result in the formation of (polycyclic) aromatic structures decorated with carboxylic acids. The combination of the reduction in $\mathrm{Mw}$ and the formation of polar functional groups are thought to be the reasons behind the improved solubility.

KEYWORDS: Humins, alkaline treatment, carbohydrates biomass, biorefinery, hydroxymethylfurfural

\section{INTRODUCTION}

Hydroxymethylfurfural (HMF), furfural (FF) and levulinic acid (LA) are biobased platform chemicals with immense potential. ${ }^{1,2}$ The production of these platform molecules in a biorefinery operation typically entails the hydrolysis of polysaccharides such as cellulose $\left(\mathrm{C}_{6}\right.$-sugars $)$ or hemicellulose $\left(\mathrm{C}_{6}\right.$ - and $\mathrm{C}_{5}$-sugars $)$ to individual sugar monomers, followed by subsequent acid-catalyzed dehydration of the $\mathrm{C}_{6}$ - and $\mathrm{C}_{5}$-sugar monomers to form HMF and FF, respectively. Under these acidic conditions, HMF is, in turn, easily rehydrated to form LA and formic acid. ${ }^{3,4}$ A major problem during such hydrothermal, acid-catalyzed treatments of sugars is the formation of insoluble, ${ }^{5}$ carbonaceous byproducts, called humins. ${ }^{3}$ The formation of humins can lead to a considerable loss of the sugar feed, thereby strongly decreasing the efficiency of the process and the economic viability of biorefineries. ${ }^{6}$ This can be ameliorated by developing (catalytic) routes for the further valorization of these humin byproducts to syngas by gasification, ${ }^{6,7}$ or to value-added chemicals by pyrolysis ${ }^{8}$ and catalytic depolymerization. For such (catalytic) conversion to proceed efficiently, both insight in the molecular structure as well as solubilization of the material is desired.

Still, relatively little is known about the complex structure of humins. $^{9-12}$ The challenges faced with regards to humin structure elucidation are actually quite similar to those previously addressed in lignin and soil chemistry. The analytical techniques developed for those complex matrices could, in principle, also be applied to humins to get more insight in their molecular structure and chemical properties. So far, most knowledge about the molecular structure of humins is based on the molecular structures proposed for hydrothermal carbons (HTC), a functional material prepared by the hydrothermal treatment of carbohydrates. In literature two prominent, but conflicting proposals can be found. Baccile et al. ${ }^{13}$ suggested that HTC has a furanic structure with methylene linkages and several oxygen functionalities, mainly based on $2 \mathrm{D}$ solid-state

Received: November 30, 2014

Revised: January 21, 2015

Published: January 30, 2015 
NMR spectra. ${ }^{13}$ On the other hand, a more condensed polycyclic aromatic structure was proposed based on elemental analysis, X-ray photoelectron spectroscopy (XPS), infrared (IR) and Raman data by Sevilla et al. ${ }^{14,15}$

As for humins, Zarubin et al. ${ }^{9}$ characterized humins obtained from different sugars and HMF by elemental analysis, IR and NMR of acetone extracts and proposed a furan-rich structure with ether and (hemi)acetal bonds as the main linkages. ${ }^{9}$ On the other hand, Lund et al. ${ }^{10,11}$ suggested that rehydration of HMF could lead to the formation of 2,5-dioxo-6-hydroxy hexanal (DHH). This compound is then thought to react with HMF and several sugar dehydration intermediates via aldol condensations leading to the formation of humins, with the inclusion of furanic rings depending on the accumulation of HMF during the dehydration reaction. ${ }^{10,11}$ We have previously reported on the formation and molecular structure of humin byproducts as a function of feedstock and processing conditions. A combination of elemental analysis, IR, solidstate NMR and pyrolysis-GC-MS (gas chromatography-mass spectrometry) data revealed an HMF-derived, furan-rich polymeric network in which the furan units are linked by short aliphatic chains and several oxygen functionalities could be identified. $^{12}$

The next step toward valorization of the humins is to improve the solubility of the material. As reported before, ${ }^{5}$ we also noted that the humins prepared under our standard conditions have a very limited solubility in common organic solvents. For example, Soxhlet extraction for $24 \mathrm{~h}$ with acetone and ethanol resulted in weight losses of only $3 \%$ and $5 \%$, respectively. This in contrast to the results reported for the humin fraction of soil organic matter (SOM), which was found to be almost completely soluble in dimethyl sulfoxide (DMSO) with $6 \% \mathrm{H}_{2} \mathrm{SO}_{4}(\mathrm{v} / \mathrm{v}) ;{ }^{16}$ our humins were hardly soluble under these conditions, however. The availability of dissolved humins would bring many advantages, as it would, for instance, greatly enhance the interaction between the substrate and a (heterogeneous) catalyst. Alkaline treatment, i.e., hydrothermal treatment of a solid in the presence of base, is a well-known method to improve the solubility of recalcitrant materials, such as SOM and lignin. ${ }^{17-20}$ For example, the solubility of humic acid and fulvic acid fractions from SOM is improved by hydrolysis of $\mathrm{C}-\mathrm{O}$ bonds at $170-250{ }^{\circ} \mathrm{C}$ in $2-5 \mathrm{M} \mathrm{NaOH}$, thereby increasing the amount of extractable components. ${ }^{17-19}$ Another example of alkaline treatment is found in lignin depolymerization, in which base is used to fragment the lignin to obtain aromatic monomers. During the alkaline treatment of lignins, rather extensive repolymerization occurs, leading to the formation of unwanted condensation products and limited monomer yields. ${ }^{21-23}$ Such possible complications aside, a similar base treatment could also prove to be very beneficial for the solubilization of humins.

Here we show that reactive dissolution of the humins is indeed possible in aqueous media using an alkaline pretreatment method. Reaction conditions have been optimized for glucose-derived humins and were tested and adjusted for fructose- and xylose-derived humins. The influence of temperature, reaction time and base concentration on the average molecular weight of the dissolved humins was monitored by gel permeation chromatography (GPC). The alkali-treated humin can be easily recovered by acidification of the liquid phase and changes in elemental composition are reported as well as the changes in molecular structure of the regenerated humins based on IR, 2D PASS ${ }^{13} \mathrm{C}$ solid-state NMR and pyrolysis-GC-MS analyses.

\section{EXPERIMENTAL SECTION}

Humin samples were prepared from an aqueous solution containing 1 $\mathrm{M}$ sugar (D-glucose, D-fructose or D-xylose) and $0.01 \mathrm{M} \mathrm{H}_{2} \mathrm{SO}_{4}$; the solution was heated to $180^{\circ} \mathrm{C}$ for $6 \mathrm{~h}$ in a $1 \mathrm{~L}$ batch autoclave (Buchi). The solid humins formed were isolated by filtration, washed with excess water and dried at RT. To remove all water-soluble components occluded in the solid, the humins were subjected to a Soxhlet extraction with water for $24 \mathrm{~h}$ and subsequently dried at $70{ }^{\circ} \mathrm{C}$ under vacuum. A detailed description of the preparation of the humins samples can be found in earlier work. ${ }^{12}$

Solubilization reactions were run in a Teflon-lined unstirred autoclave vessel filled with $0.5 \mathrm{~g}$ of glucose-derived humin and 50 $\mathrm{mL}$ of $\mathrm{NaOH}$ solution and heated in an oven. Stirring of the reaction mixture is expected to speed up the solubilization of humins, but could not be applied in our setup. Reaction parameters were varied: time 3$24 \mathrm{~h}, \mathrm{NaOH}$ concentration $0-2 \mathrm{M}$, temperature $150-240{ }^{\circ} \mathrm{C}$. Relevant reactions were repeated with fructose- and xylose-derived humins and conditions were independently optimized. The reaction mixture was cooled to RT, filtered and any remaining residues were washed with water and dried at RT. The amount of residue was weighed and expressed as wt $\%$ of the amount of starting material.

For further characterization of the solubilized humins from the different feedstocks, $5 \mathrm{~g}$ (glucose-, fructose-, or xylose-derived) of humin was treated with $80 \mathrm{~mL}$ of $2 \mathrm{M} \mathrm{NaOH}$ at $240^{\circ} \mathrm{C}$ for $3 \mathrm{~h}$. The humins were precipitated from the solution by acidification to $\mathrm{pH} 1$ with $6 \mathrm{M} \mathrm{H}_{2} \mathrm{SO}_{4}$, isolated by filtration, washed with $6 \mathrm{~L}$ of water and dried under vacuum for $24 \mathrm{~h}$ at $70{ }^{\circ} \mathrm{C}$.

The aqueous phase was analyzed by GPC on an alkaline SEC by a Waters Alliance system equipped with a manually packed column (4.6 $\times 30 \mathrm{~cm}$ ) with ethylene glycolmethacrylate copolymer TSK gel Toyopearl HW-55F according to the work of Gosselink et al. ${ }^{52}$ The system was operated at $40{ }^{\circ} \mathrm{C}$ with $0.5 \mathrm{M} \mathrm{NaOH}$ eluent at a flow rate

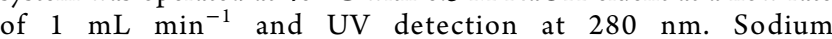
polystyrenesulfonates ( $\mathrm{Mw}$ range 891 to $976000 \mathrm{Da}$ ) were used for calibration of the molar mass distribution. Humin samples were diluted to a concentration of $1 \mathrm{~g} \mathrm{~mL}^{-1}$ using $0.5 \mathrm{M} \mathrm{NaOH}$.

Attenuated total reflectance (ATR)-IR spectra were recorded on a Bruker Tensor 37 IR spectrometer using a PIKE MIRacle ATR accessory with a diamond crystal. For each spectrum, 32 scans with a resolution of $4 \mathrm{~cm}^{-1}$ were averaged. Elemental analyses (CHNS) were performed at the University of Groningen. The oxygen content was calculated by difference. The ${ }^{13} \mathrm{C}$ solid-state NMR spectra were recorded at the Radboud University Nijmegen. All spectra were measured on a $300 \mathrm{MHz}$ solid-state NMR spectrometer using a 7.5 $\mathrm{mm}$ double resonant chemagnetics APEX probe, tuned at $75.45 \mathrm{MHz}$ for carbon. All spectra were obtained using ramped CPMAS at a radio frequency (rf) field of $55 \mathrm{kHz}$ for carbon and $51 \mathrm{kHz}$ for protons. Proton decoupling during acquisition was accomplished with a Spinal64 sequence at an rf-field of $55 \mathrm{kHz}$, optimized to a pulse width and phase of $9 \mu \mathrm{s}$ and $7^{\circ}$, respectively, and magic angle scanning speeds were $4 \mathrm{kHz}$. After cross-polarization, a 2D PASS sequence was used to separate the spinning sidebands, employing cogwheel phase cycling. ${ }^{53}$ The NMR spectra were normalized to a total area of 1 .

Analytical programmed temperature vaporization (PTV) GC-MS of humins was conducted with a HP 5890 GC Series II system equipped with a 5972 MS detector, and the PTV was controlled by an Optic 2 device. Typically, $1 \mathrm{mg}$ of sample was used. The pyrolysis temperature program started at $40{ }^{\circ} \mathrm{C}$ followed by heating to $600{ }^{\circ} \mathrm{C}$ at a rate of $16^{\circ} \mathrm{C} \mathrm{min}{ }^{-1}$, and finally held at $600{ }^{\circ} \mathrm{C}$ for $0.5 \mathrm{~min}$. After pyrolysis, the products were transferred into a capillary column (Agilent Technologies VF-5ms, $30 \times 0.25 \times 1.0$ ) by a GC injector (split 50:1). Helium was used as the carrier gas at a flow rate of $1 \mathrm{~mL}$ $\mathrm{min}^{-1}$. The following GC temperature program was applied: starting temperature of $40^{\circ} \mathrm{C}$ for 5 min followed by heating at a rate of $10^{\circ} \mathrm{C}$ $\mathrm{min}^{-1}$ to a final temperature of $250^{\circ} \mathrm{C}$. The MS detector was operated in the electron ionization mode $(70 \mathrm{eV})$ with an interface temperature 


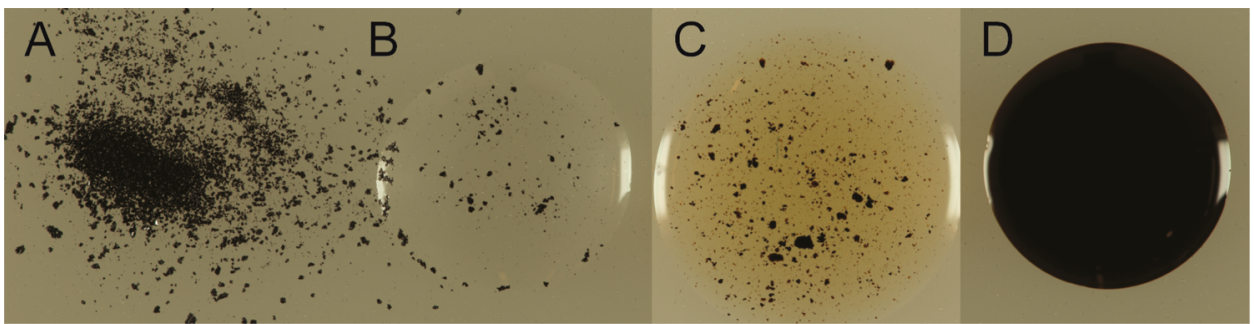

Figure 1. (A) Glucose-derived humins. (B) Droplet of a glucose-derived humins suspended in water at RT. (C) Droplet of glucose-derived humins suspended in $0.5 \mathrm{M} \mathrm{NaOH}$ at RT. (D) Droplet of a solution of glucose-derived humins after reactive solubilization by alkaline pretreatment at 240 ${ }^{\circ} \mathrm{C}$.

$280{ }^{\circ} \mathrm{C}$. A scan range of $m / z 35-400$ was applied. Pyrolysis products were identified by comparison with mass spectra of authentic compounds and masses.

\section{RESULTS AND DISCUSSION}

Reactive Solubilization of Humins. Humin samples were prepared as described in previous work. ${ }^{12}$ and subsequently subjected to an alkaline pretreatment based on a method used in soil chemistry. ${ }^{17,18}$ Any residual solids were isolated by filtration, washed and dried before characterization.

In a typical reaction, glucose-derived humins were suspended in $0.5 \mathrm{M} \mathrm{NaOH}$ at $240{ }^{\circ} \mathrm{C}$ for $3 \mathrm{~h}$. After reaction and cooling to $\mathrm{RT}$, the humins were completely dissolved and a dark brown solution was obtained (Figure 1, Table 1 run 4). Lowering the temperature to $200^{\circ} \mathrm{C}$ and slightly extending the reaction time to $3.5 \mathrm{~h}$ also led to complete solubilization of the humins at this temperature (run 3). The reaction time was varied from 2 to 24 h at $200{ }^{\circ} \mathrm{C}$ and from 1 to $16 \mathrm{~h}$ at $240{ }^{\circ} \mathrm{C}$. At $240{ }^{\circ} \mathrm{C}$, a reaction

Table 1. Optimization of Reaction Conditions for the Solubilization of Glucose-Derived Humins

\begin{tabular}{|c|c|c|c|c|c|c|}
\hline run \# & $\begin{array}{c}\text { time } \\
(\mathrm{h})\end{array}$ & $\begin{array}{l}\text { temp } \\
\left({ }^{\circ} \mathrm{C}\right)\end{array}$ & $\underset{(\mathrm{M})}{\mathrm{NaOH}}$ & $\begin{array}{c}\mathrm{Mw}^{a} \\
(\mathrm{~g} / \mathrm{mol})\end{array}$ & $\mathrm{PD}^{a}$ & $\begin{array}{l}\text { residue } \\
\text { (wt \%) }\end{array}$ \\
\hline \multicolumn{7}{|c|}{ influence of temperature } \\
\hline 1 & 3 & 150 & 0.5 & & & 94 \\
\hline 2 & 3 & 175 & 0.5 & & & 50 \\
\hline 3 & 3.5 & 200 & 0.5 & 17400 & 12.2 & 0 \\
\hline 4 & 3 & 240 & 0.5 & 6100 & 7.4 & 0 \\
\hline \multicolumn{7}{|c|}{ influence of $[\mathrm{NaOH}]$} \\
\hline 5 & 3 & 240 & 0 & & & 86 \\
\hline 6 & 3.5 & 200 & 0 & & & 93 \\
\hline 7 & 3.5 & 200 & 0.1 & & & 65 \\
\hline 8 & 3.5 & 200 & 0.25 & 24100 & 15.4 & 0 \\
\hline 9 & 3.5 & 200 & 1 & 19000 & 13.9 & 0 \\
\hline 10 & 3.5 & 200 & 2 & 13400 & 10.5 & 0 \\
\hline \multicolumn{7}{|c|}{ influence of time } \\
\hline 11 & 2 & 200 & 0.5 & & & \\
\hline 12 & 3 & 200 & 0.5 & 23000 & 14.9 & 2 \\
\hline 13 & 6 & 200 & 0.5 & 11900 & 10.2 & 0 \\
\hline 14 & 16 & 200 & 0.5 & 7800 & 7.9 & 0 \\
\hline 15 & 24 & 200 & 0.5 & 7500 & 8.8 & 0 \\
\hline 16 & 1 & 240 & 0.5 & & 6.6 & 86 \\
\hline 17 & 2 & 240 & 0.5 & 8600 & 9.1 & 0 \\
\hline 18 & 3 & 240 & 0.5 & 6100 & 7.4 & 0 \\
\hline 19 & 4 & 240 & 0.5 & 4800 & 6.8 & 0 \\
\hline 20 & 6 & 240 & 0.5 & 4300 & 6.7 & 0 \\
\hline 21 & 16 & 240 & 0.5 & 3300 & 6.5 & 0 \\
\hline
\end{tabular}

${ }^{a}$ Sodium polystyrenesulfonates were used for calibration of the molar mass distribution. time of $2 \mathrm{~h}$ was found to be sufficient to dissolve the humins completely (run 17), whereas at $200{ }^{\circ} \mathrm{C}$, a reaction time of 3.5 $\mathrm{h}$ is required. A further decrease in temperature to 175 and 150 ${ }^{\circ} \mathrm{C}$ led to the solubilization of only 50 and 6 wt \% of the humins, respectively, after $3 \mathrm{~h}$ (run 1 and 2).

A blank experiment showed that base is indeed required for solubilization of the humins, as after treatment of the humin in $\mathrm{pH}$ neutral water, only 7 and $14 \mathrm{wt} \%$ of the humin was dissolved at 200 and $240{ }^{\circ} \mathrm{C}$, respectively (runs 5 and 6). Variation of the base concentration from 0.1 to $2 \mathrm{M}$ showed that a minimal base concentration of $0.25 \mathrm{M}$ is needed to solubilize the humins completely (runs 7-10).

Only for those experiments in which complete solubilization was achieved, the liquid phase was analyzed by alkaline GPC to assess the influence of reaction parameters on the extent of depolymerization and the distribution of molecular weights and sizes (Table 1). This is, to our best knowledge, the first report of liquid-phase analysis of solubilized humins obtained by the acid-catalyzed dehydration of monosaccharides. Please note that the weight-average molecular weight $(\mathrm{Mw})$ and polydispersity (PD) values obtained should be used to assess relative rather than absolute changes in molecular weight and $\mathrm{PD}$, as the parent humin is insoluble and its molecular weight thus unknown; a proper standard for humins is furthermore not available.

The GPC data showed that depolymerization is more efficient at higher temperatures, with the average molecular weight of the humins treated at $200{ }^{\circ} \mathrm{C}$ for $3.5 \mathrm{~h}$ being almost 3 times higher than the $\mathrm{Mw}$ of humins treated at $240{ }^{\circ} \mathrm{C}$ for $3 \mathrm{~h}$. Further analysis of the effect of reaction time at 200 and $240{ }^{\circ} \mathrm{C}$ showed that the Mw and PD gradually decrease with increasing reaction time and reach a plateau. This indicates that no significant repolymerization, as often reported for lignins in alkaline depolymerization processes, ${ }^{21-23}$ occurs at high temperatures or long reaction times (Figure 2). Increased base concentration, on the other hand, seemed to have little effect on the decrease of $\mathrm{Mw}$ and PD. The upper solubility limit of the humins in base was not determined, but these results show that extending the reaction time can allow for the solubilization of larger amounts of the humins.

The mildest conditions required for complete solubilization of glucose-derived humins were next tested for dissolving fructose- and xylose-derived humins. These humins proved to be considerably more recalcitrant to alkaline treatment, however, as such a treatment at $200{ }^{\circ} \mathrm{C}$ for $3.5 \mathrm{~h}$ in $0.5 \mathrm{M}$ $\mathrm{NaOH}$ only dissolved $40-50$ wt \%. Increasing the reaction temperature to $240{ }^{\circ} \mathrm{C}$ did nonetheless result in complete solubilization also of these humins (Table 2). The recalcitrance of, in particular, the fructose-derived humins, is remarkable, because various techniques including ${ }^{13} \mathrm{C}$ solid-state $\mathrm{NMR}$, 


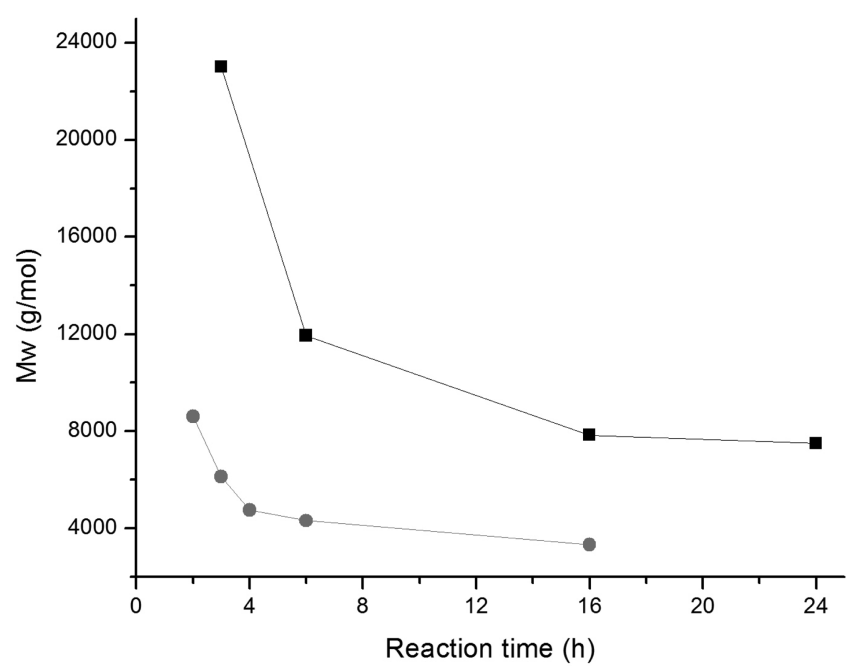

Figure 2. Changes in average molecular weight of glucose-derived humins as a function of reaction time at $200{ }^{\circ} \mathrm{C}$ (black squares) and $240{ }^{\circ} \mathrm{C}$ (gray dots) in $0.5 \mathrm{M} \mathrm{NaOH}$ ( $\mathrm{Mw}$ determined by GPC relative to polystyrenes standards).

Table 2. Alkaline Pretreatment of Glucose-, Fructose- and Xylose-Derived Humins

$\begin{array}{lcccccc}\begin{array}{l}\text { humin } \\ \text { source }\end{array} & \begin{array}{c}\text { time } \\ (\mathrm{h})\end{array} & \begin{array}{c}\text { temperature } \\ \left({ }^{\circ} \mathrm{C}\right)\end{array} & \begin{array}{c}\mathrm{NaOH} \\ (\mathrm{M})\end{array} & \begin{array}{c}\mathrm{Mw}^{a} \\ (\mathrm{~g} / \mathrm{mol})\end{array} & \mathrm{PD}^{a} & \begin{array}{c}\text { residue } \\ (\text { wt \%) }\end{array} \\ \text { glucose } & 3.5 & 200 & 0.5 & 17400 & 12.2 & 0 \\ \text { fructose } & 3.5 & 200 & 0.5 & & & 56 \\ \text { xylose } & 3.5 & 200 & 0.5 & & & 41 \\ \text { glucose } & 3 & 240 & 0.5 & 6100 & 7.4 & 0 \\ \text { fructose } & 3 & 240 & 0.5 & 6700 & 8.8 & 0 \\ \text { xylose } & 3 & 240 & 0.5 & 6900 & 9.1 & 0\end{array}$

${ }^{a}$ Sodium polystyrenesulfonates were used for calibration of the molar mass distribution.

ATR-IR and elemental analysis showed their molecular structure to actually be very similar to glucose-derived humins. ${ }^{12}$ The recalcitrance of xylose-derived humins to dissolve is less surprising since the same study indicated that these humins have a more conjugated structure with more direct linkages between the furan rings, which may explain the higher recalcitrance to the alkaline treatment. Another explanation would be that the original humin samples derived from the various monomeric sugars already show large differences in molecular weight, something which unfortunately cannot be checked due to their insolubility. Higher humin yields were reported for fructose-derived humins, though, which might indicate that these humins are indeed more crosslinked or less soluble than the glucose-derived humins. Furthermore, the average molecular weight of the oligomers that were still found in solution after acid-catalyzed dehydration of fructose was lower than for the other sugars, again pointing at lower solubility of the fructose-derived humins. ${ }^{12}$

Characterization of Residual Humins. For those reactions for which solubilization of the glucose-derived humins was incomplete (runs 1, 2, 5-7, Table 1), the solid residue was isolated by filtration, washed, dried and analyzed by ATR-IR spectroscopy (Figure 3). We and others have previously reported on the assignment of the ATR-IR spectra of humins. ${ }^{11,12}$ The ATR-IR spectrum of the residue obtained after reaction without base showed only minor changes in the molecular structure. The ratio between the peak assigned to the

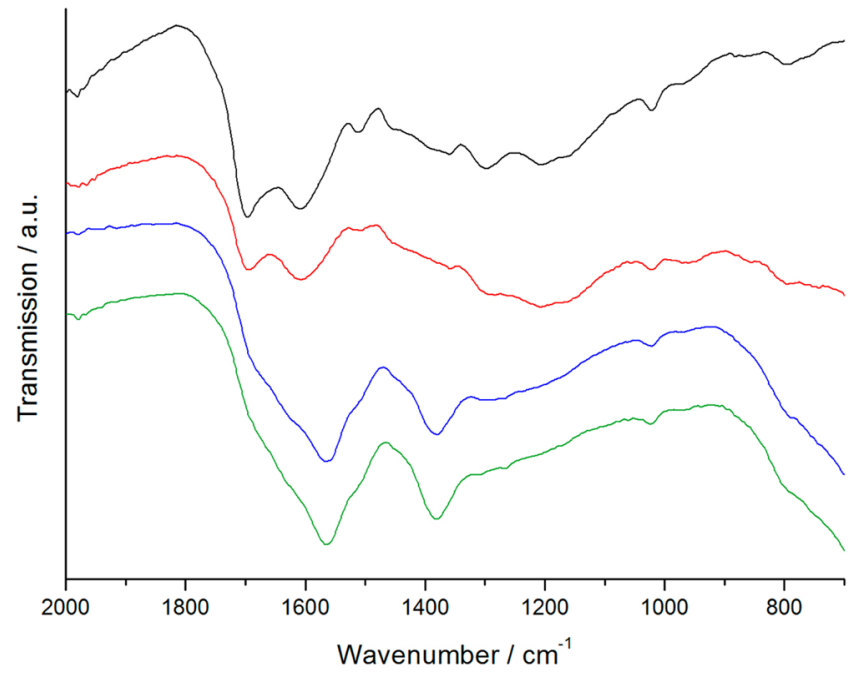

Figure 3. ATR-IR spectra of residual humins after alkaline pretreatment for $3 \mathrm{~h}$, in $0.5 \mathrm{M} \mathrm{NaOH}$ at $150{ }^{\circ} \mathrm{C}$ (green) and for $3.5 \mathrm{~h}$ in $0.1 \mathrm{M} \mathrm{NaOH}$ at $200{ }^{\circ} \mathrm{C}$ (blue). The residual humin obtained from a blank reaction without base for $3.5 \mathrm{~h}$ at $200^{\circ} \mathrm{C}$ (red) as well as the parent glucose-derived humin (black) are included for comparison.

carbonyl stretch vibration of a carboxylic acid at $1700 \mathrm{~cm}^{-1}$ and the ring stretch of aromatics and furans at $1600 \mathrm{~cm}^{-1}$ is slightly changed after treatment in water, though; pointing at either a loss of $\mathrm{C}=\mathrm{O}$ groups or an increase of $\mathrm{C}=\mathrm{C}$ bonds. The peak at $1510 \mathrm{~cm}^{-1}$ could be assigned to ring stretch vibrations from a furan or arene ring. Assignment to the furanic in-phase ring stretch is more likely in combination with the peaks observed at 1020 and $800 \mathrm{~cm}^{-1}$. This peak is slightly weaker for alkalitreated humins which might indicate changes in the furanic network. Some signals in the $\mathrm{C}-\mathrm{O}$ stretch area (1300-1000 $\mathrm{cm}^{-1}$ ) are weakened, which points at changes in the oxygen functionalities. The blank spectra show that the increase in $\mathrm{C}=$ $\mathrm{C}$ bonds from aromatic rings, which points at the formation of arene rings at the expense of furanic rings, and $\mathrm{O}-\mathrm{C}$ functional groups is partially caused by hydrothermal reactions. A similar effect was observed for HTC at extended reaction times, with dehydration and aromatization of the sample being observed. $^{15}$ However, aromatization was not as strong as observed for the humins that were completely solubilized by alkaline pretreatment (see below), showing that aromatization is not a purely thermal effect.

The residues found after alkaline pretreatment at $200{ }^{\circ} \mathrm{C}$ in $0.1 \mathrm{M} \mathrm{NaOH}$ and treatment in $0.5 \mathrm{M} \mathrm{NaOH}$ at $150{ }^{\circ} \mathrm{C}$ have almost identical ATR-IR spectra. These spectra are very different from the spectra of the parent humin and are dominated by the strong peaks at 1565 and $1385 \mathrm{~cm}^{-1}$, assigned to the antisymmetric and symmetric stretch of carboxylate anions $\left(\mathrm{COO}^{-}\right)$, respectively. A shoulder around $1700 \mathrm{~cm}^{-1}$ is also seen in the ATR-IR spectrum of the residue, indicating that some other carbonyl groups, most likely ketones, are present as well. Other parts of the spectrum were difficult to assign because the peaks from $\mathrm{COO}^{-}$dominate the signals. Such carboxylic acids were already detected in the parent humins but only in minor amounts; the new carboxylic acid groups might be the result of a reaction with the hydroxide in a Cannizzaro-like disproportionation where aromatic aldehydes react with hydroxide to form a carboxylic acid, as well as an alcohol. 


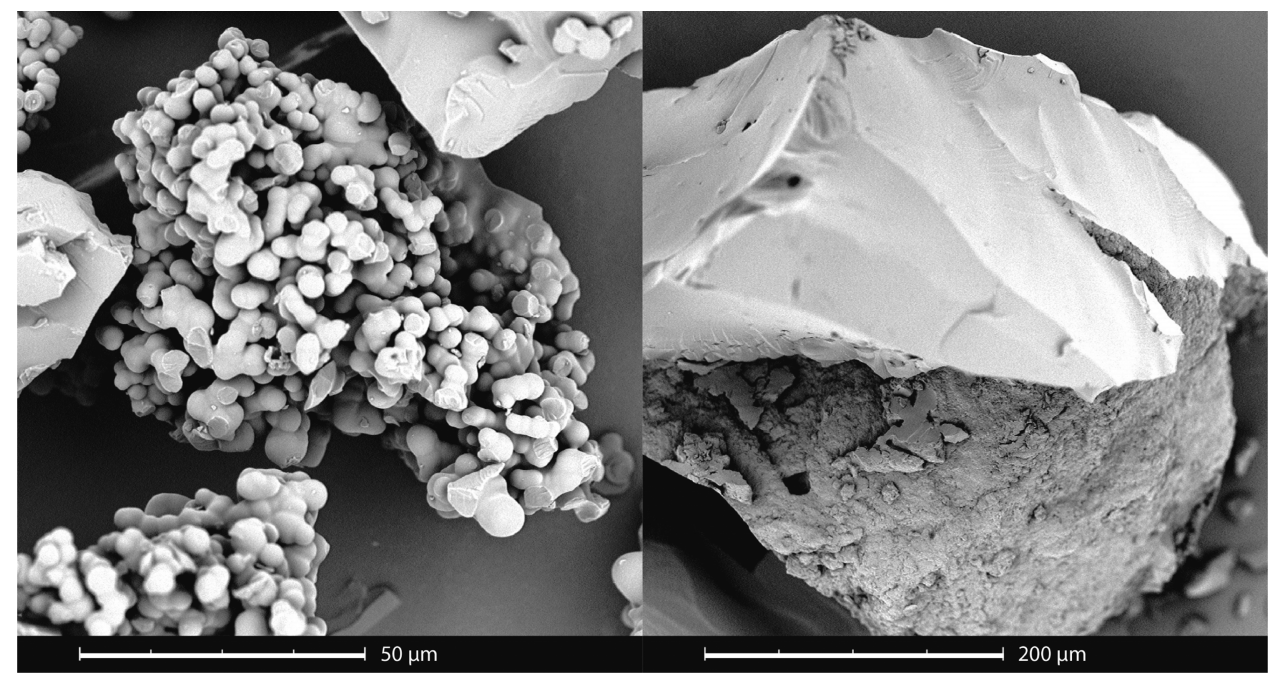

Figure 4. SEM images of the parent humin (left) and recovered glucose-derived humin after alkaline pretreatment and precipitation by acidification (right).

\section{Characterization of Recovered Alkali-Treated Humins} by SEM and Elemental Analysis. Soluble humins obtained from solubilization reactions run at $240{ }^{\circ} \mathrm{C}$ in $0.5 \mathrm{M} \mathrm{NaOH}$ for $3 \mathrm{~h}$ were taken for the characterization studies, as these conditions are sufficient to solubilize all three humin samples completely. After alkaline treatment, the solubilized humins stay in solution down to a $\mathrm{pH}$ of about 7 . Indeed, the humin can be precipitated by further acidification of the liquid phase with $\mathrm{H}_{2} \mathrm{SO}_{4}$ to $\mathrm{pH} 1$ (redissolution requires the $\mathrm{pH}$ to be $\geq 7$ ). The recovered humins were subsequently washed, dried at 70 ${ }^{\circ} \mathrm{C}$ under vacuum and characterized by several analytical techniques. This way, about 75 wt $\%$ of the original humin intake could be recovered.

Figure 4 shows the SEM images of the parent humin and humin recovered after alkaline pretreatment. It is clear that the typical spherical morphology of the parent humin is completely lost after alkaline pretreatment, showing that the humins indeed were completely solubilized by treatment with base.

The elemental compositions of the parent and recovered, alkaline-treated humins are given in Table 3. The data, visualized by a van Krevelen plot in Figure 5, clearly shows loss of oxygen content with a concomitant slight increase in $\mathrm{H} /$ $\mathrm{C}$, indicating net loss of oxygen functionalities in the structure. These changes in the elemental composition are similar to the differences observed in elemental composition of cellulose samples after thermal treatment in neutral and alkaline media

Table 3. Elemental Analysis of Glucose-, Fructose- and Xylose-Derived Humins before and after Alkaline Treatment $^{a}$

$\begin{array}{lcccccc} & \text { wt \% C } & \text { wt \% } \mathrm{H} & \text { wt \% S } & \text { wt \% } \mathrm{O}^{b} & \mathrm{H} / \mathrm{C} & \mathrm{O} / \mathrm{C} \\ \begin{array}{l}\text { original humin } \\ \text { glucose humin }\end{array} & 64.55 & 4.27 & <0.01 & 31.19 & 0.79 & 0.36 \\ \text { fructose humin } & 65.02 & 4.13 & <0.01 & 30.86 & 0.76 & 0.36 \\ \text { xylose humin } & 66.70 & 3.83 & <0.01 & 29.48 & 0.69 & 0.33 \\ \text { recovered alkali-treated humin } & & & & & \\ \text { glucose humin } & 71.96 & 4.75 & <0.01 & 23.29 & 0.82 & 0.26 \\ \text { fructose humin } & 71.51 & 4.66 & <0.01 & 23.83 & 0.78 & 0.25 \\ \text { xylose humin } & 72.23 & 4.72 & <0.01 & 23.04 & 0.79 & 0.24\end{array}$

${ }^{a} N<0.01$ wt $\% .{ }^{b}$ Calculated by difference.

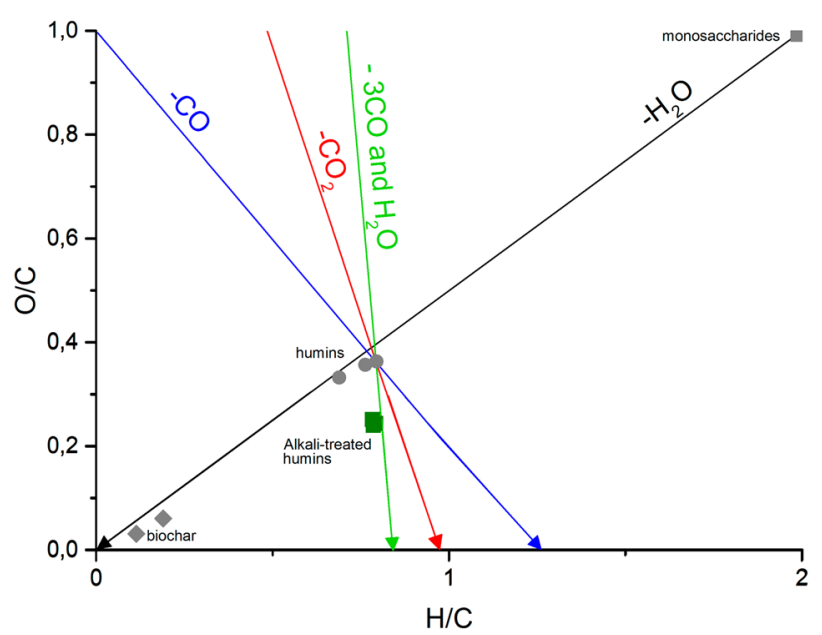

Figure 5. van Krevelen plot showing changes in the elemental composition of humins (gray circle) formed during the acid-catalyzed dehydration of monosaccharides (gray square). Complete dehydration of sugars, indicated by the black arrow, yields biochar (gray diamonds). Alkaline treatment of humins (green squares) changes the elemental composition; possible pathways are decarboxylation (red arrow), loss of $\mathrm{CO}$ (blue arrow) and a combination of dehydration and CO loss (green line).

$\left(\mathrm{pH} \mathrm{11)} .^{24}\right.$ The decrease in the $\mathrm{O} / \mathrm{C}$ ratio and increase in the $\mathrm{H} / \mathrm{C}$ ratio indicate that elimination of $\mathrm{CO}$ or $\mathrm{CO}_{2}$ occurs during alkaline treatment of the humins. ${ }^{25}$ Such a decarboxylation pathway (red line in Figure 5) is close to the observed changes in elemental composition, however, it does not fit with the increase in carboxylic acid content that is observed and discussed below. The van Krevelen plot shows that exclusive loss of $\mathrm{CO}$ does not fit with the observed elemental composition neither (blue line in Figure 5). Instead, the data suggests a combination of dehydration and loss of $\mathrm{CO}$ during the alkaline treatment of humins (green line in Figure 5).

Molecular Structure of Alkali-Treated Humins: ATR-IR, ${ }^{13} \mathrm{C}$ Solid-State NMR and Pyrolysis-GC-MS. The ATR-IR spectra of three alkali-treated humin samples (Figure 6) proved to be very similar. After acidification of the liquid phase, sulfates arising from sulfuric acid could be present in the sample, but 


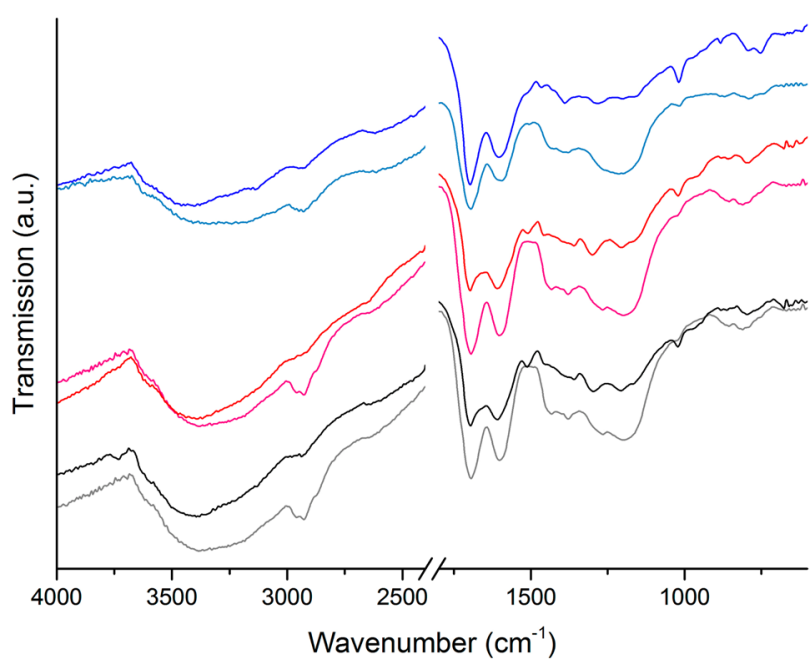

Figure 6. ATR-corrected IR spectra of original humins (dark colors) and alkali-treated (light colors) humins derived from glucose (black), fructose (red) and xylose (blue).

comparison to the ATR-IR spectrum of $\mathrm{Na}_{2} \mathrm{SO}_{4}$ and $\mathrm{H}_{2} \mathrm{SO}_{4}$ showed that major contributions from sulfates in the ATR-IR spectra of alkali-treated humins can be excluded; this is further confirmed by the low sulfur content of the humins ( $<0.01 \mathrm{wt} \%$, Table 3).

Compared to the ATR-IR spectra of the parent humins, major changes in the molecular structure are observed, though (Figure 6). The $\mathrm{O}-\mathrm{H}$ stretch band is shifted slightly to lower wavenumbers and has become very broad, which again could point at the formation of carboxylic acids. At $3000-2800 \mathrm{~cm}^{-1}$, clear $\mathrm{C}-\mathrm{H}$ stretch vibrations can be seen which are much more pronounced than in the ATR-IR spectra of the parent humins. The signal at $1700 \mathrm{~cm}^{-1}$, assigned to $\mathrm{C}=\mathrm{O}$ bonds, is slightly broader in the alkali-treated sample. The peak at 1610 $\mathrm{cm}^{-1}$, attributed to a $\mathrm{C}=\mathrm{C}$ ring stretch vibration, is shifted slightly to lower wavenumbers after alkaline pretreatment. For the glucose- and fructose-derived humins, the signals from $\mathrm{C}=$ $\mathrm{C}$ and $\mathrm{C}=\mathrm{O}$ stretch vibrations are much stronger in the alkalitreated humins, indicating an increase in the amount of these functional groups or the formation of a more uniform structure. A distinct difference is the disappearance of the peak at 1510 $\mathrm{cm}^{-1}$ in glucose- and fructose-derived humin and of the signal at $1465 \mathrm{~cm}^{-1}$ in xylose-derived humin after alkaline pretreatment. This, together with a decrease of the peak at $1020 \mathrm{~cm}^{-1}$ ascribed to furan ring deformation, and a shift of the peaks around $800 \mathrm{~cm}^{-1}$ from $\mathrm{C}-\mathrm{H}$ out of plane vibrations of aromatic rings points at a decrease in furanic content after alkaline pretreatment. The strongest changes are observed in the $\mathrm{C}-\mathrm{O}$ stretch region, however, as several details between 1300 and $1000 \mathrm{~cm}^{-1}$ (C-O stretch from alcohols and ethers) have disappeared. In the same region, a broad peak centered around $1150 \mathrm{~cm}^{-1}$ appeared, which can be ascribed to a hydroxyl group bonded to $\mathrm{C}=\mathrm{C}$ or to an aromatic ring, i.e., a phenolic $\mathrm{OH}$.

${ }^{13} \mathrm{C}$ solid-state NMR studies provided further insight into the changes in the molecular structure of the humins upon alkaline treatment. The NMR spectra of the alkali-treated humins were recorded using a two-dimensional phase adjusted spinning sidebands (2D PASS) pulse sequence that separates the spinning sidebands from the center band into a second dimension (Figures 7 and 8). The sidebands arise from the

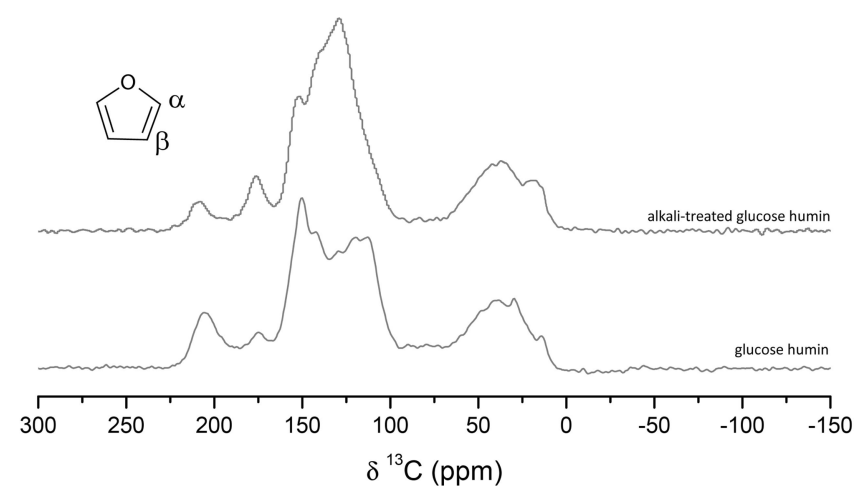

Figure 7. Sheared-sum projections of the $2 \mathrm{D}$ PASS solid-state ${ }^{13} \mathrm{C}$ NMR spectra of glucose-derived humin before and after alkaline treatment. Insert: $\mathrm{C} \alpha$ and $\mathrm{C} \beta$ in the furanic ring.

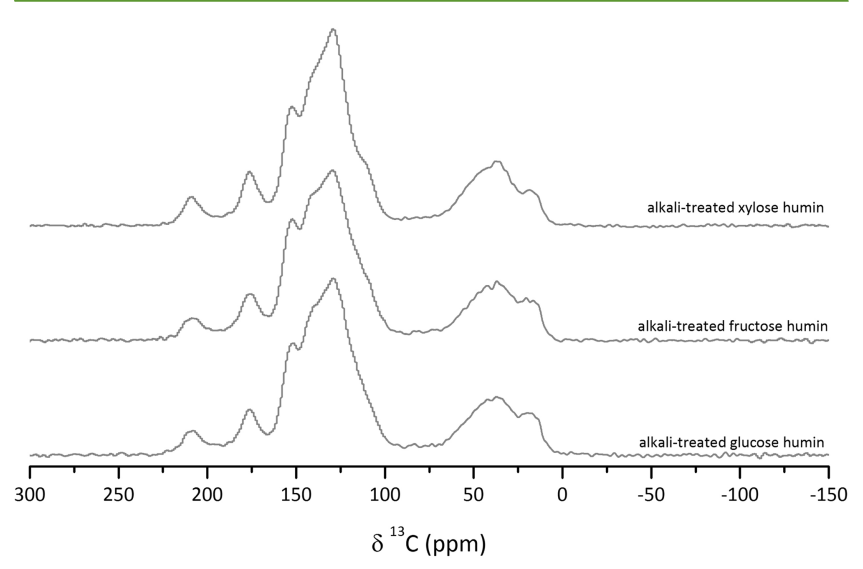

Figure 8. Sheared-sum projections of the $2 \mathrm{D}$ PASS ${ }^{13} \mathrm{C}$ solid-state NMR spectra of alkali-treated glucose-, fructose- and xylose-derived humin.

anisotropy in the chemical shifts, which is large for groups such as aromatic and carbonyl functional groups. ${ }^{12,26,27}$ The 2D PASS solid-state NMR spectra of the original humins and their interpretation have been reported before. ${ }^{12}$ A pattern characteristic of oxygen-containing aromatic rings was observed which is ascribed to furanic rings, based on the typical signals for $\mathrm{C} \alpha$ and $\mathrm{C} \beta$ observed at $\delta=140-150 \mathrm{ppm}$ and $\delta=110-120 \mathrm{ppm}$, respectively, which were observed in a $1: 1$ ratio. $^{28}$

The solid-state NMR spectra of glucose humins before and after alkaline treatment (Figure 7) again confirm the significant chemical changes in the molecular structure of the humin. Major changes can be seen in the $\mathrm{C}=\mathrm{C}$ region $(\delta=90-160$ ppm), especially the peaks from furanic $\mathrm{C} \alpha$ and $\mathrm{C} \beta$ were less intense than observed in the parent humins. A strong, new signal centered around $\delta=130 \mathrm{ppm}$ appeared, which can be ascribed to a conjugated aromatic network. ${ }^{28,29}$ The increase in intensity of the signal at $\delta=176 \mathrm{ppm}$ furthermore points at the formation of (additional) carboxylic acid groups; note that the assignment of this peak to ester functional groups is considered unlikely in strong alkali. The formation of these ionizable carboxylic acid groups, together with the considerable reduction in molecular weight, can explain the increased solubility of the humins at higher $\mathrm{pH}$. The peak assigned to ketones and aldehydes at $\delta=209 \mathrm{ppm}$ has become much less intense for the alkali-treated humin. Finally, the changes in the aliphatic region are remarkably small and the ratio between saturated and unsaturated (aromatic) carbons is very similar for the humins 
before and after alkaline treatment. The low, undefined intensity in the alcohol/ether region seen for the parent humins, has almost disappeared after alkaline pretreatment, showing that any such bonds were hydrolyzed during the treatment.

Although the solid-state NMR spectra of the parent humins from different sugar feeds showed clear differences, the spectra of the three alkali-treated humins are overall very similar (Figure 8). Small differences can still be seen though for the alkali-treated humins originating from $\mathrm{C}_{6^{-}}$or $\mathrm{C}_{5}$-sugars. ${ }^{12} \mathrm{An}$ additional shoulder appeared in the alkali-treated xylose humin spectrum at $\delta=110 \mathrm{ppm}$, whereas the shoulder at $\delta=141 \mathrm{ppm}$ on the main aromatic peak is weaker. These shoulders originate from nonsubstituted $\mathrm{C} \beta$ and $\mathrm{C} \alpha$ in furan, respectively. ${ }^{13,28}$

To further support the assignments made for the 2D PASS ${ }^{13} \mathrm{C}$ NMR spectra of the alkali-treated humins, spectra were recorded with two different cross-polarization (CP) mixing times as well as with an interrupted decoupling (ID) pulse sequence. The spectra with a short $\mathrm{CP}$ mixing time ( $5 \mu \mathrm{s})$ mainly show protonated carbons, while longer $\mathrm{CP}$ mixing times (1 ms) will show all carbons and give the complete NMR spectrum. It should be noted in this respect that the amount of methyl groups is always underestimated with $\mathrm{CP}$ methods due their fast rotation. ${ }^{30}$ In addition, further elongation of the $\mathrm{CP}$ time ( $2 \mathrm{~ms}$ ) combined with an interrupted decoupling pulse sequence $^{31,32}$ should, in principle, selectively show only the nonprotonated carbons; note that some methyl or methoxy groups can also appear in an ID spectrum as their fast rotation reduces the $\mathrm{CH}$ dipolar couplings.

The CP (ID) spectra of alkali-treated xylose-derived humins are shown in Figure 9 to illustrate what information can be

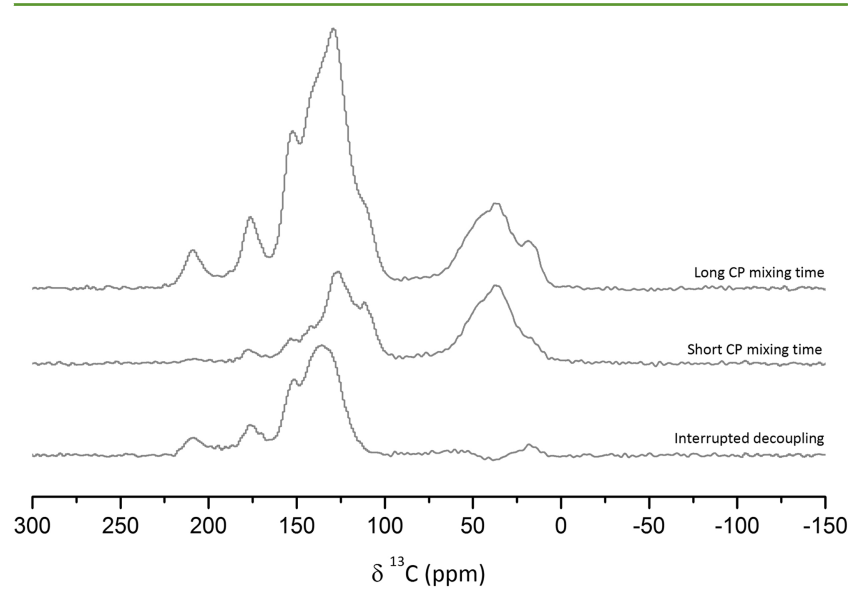

Figure 9. $2 \mathrm{D}$ PASS ${ }^{13} \mathrm{C}$ solid-state NMR spectra of alkali-treated xylose humin recorded using long $\mathrm{CP}$ time, short $\mathrm{CP}$ time and interrupted decoupling.

gained as a function of mixing time and decoupling. In addition to the strong signal expected for the aliphatic carbons at around $\delta=37 \mathrm{ppm}$ that is seen with a short $\mathrm{CP}$ mixing time, protonated carbons from furan are observed at $\delta=111 \mathrm{ppm}$ and $\delta=142 \mathrm{ppm}$ in the aromatic region, from unsubstituted $\mathrm{C} \beta$ and $\mathrm{C} \alpha$, respectively. ${ }^{28}$ These signals are similar to the chemical shifts expected for $\mathrm{C} \alpha$ and $\mathrm{C} \beta$ in benzofuran, ${ }^{33}$ whose presence would be in agreement with the more aromatic character of the treated humins; the presence of nonfused furanic rings cannot be excluded, though. The peak at $\delta=127 \mathrm{ppm}$ can be assigned to protonated carbon atoms in poly aromatic structures, ${ }^{34}$ and the signal at $\delta=153 \mathrm{ppm}$ might be caused by pyrone-like structures. ${ }^{35}$ Furthermore, a weak signal around $\delta=176 \mathrm{ppm}$ was observed as well, which might indicate the presence of some aldehyde functional groups probably connected to a furan ring. ${ }^{36}$

The ID spectrum shows a signal for the methyl groups at around $\delta=17 \mathrm{ppm}$, but no quaternary $\mathrm{sp}^{3}$ carbons. The broad signal centered around $\delta=141 \mathrm{ppm}$ suggests the presence of nonprotonated carbons in poly aromatic structures, ${ }^{34}$ whereas the peak at $\delta=151 \mathrm{ppm}$ can be ascribed to substituted $\mathrm{C} \alpha$ in furan $^{28,33}$ or a $\mathrm{C} \alpha$ in phenol, ${ }^{37}$ two options which are actually difficult to distinguish in $1 \mathrm{D}^{13} \mathrm{C}$ solid-state $\mathrm{NMR}^{38}$ The $\mathrm{C}=\mathrm{O}$ at $\delta=176 \mathrm{ppm}$ in the interrupted decoupling spectrum is again assigned to carboxylic acid groups, whereas the fact that the signal at $\delta=209 \mathrm{ppm}$, not seen in the short CP spectrum, is actually seen with the ID signal proves that the $\mathrm{C}=\mathrm{O}$ carbon is nonprotonated and should be ascribed to ketones. In conclusion, the ${ }^{13} \mathrm{C}$ solid-state NMR spectra of alkali-treated humins further confirm the formation of an arene-rich structure with an increase in carboxylic acid functionalities.

Pyr-GC-MS data was previously reported for the parent humins and showed several low molecular weight furanic compounds to be released upon pyrolysis, supporting our proposal of a furan-rich molecular structure. ${ }^{8,12}$ Pyrolysis of the alkali-treated humins yielded more substituted benzenes and less furanics, further supporting the more arene-like structure indicated by ${ }^{13} \mathrm{C}$ solid-state NMR (Figure 10). ${ }^{8,12}$ As expected from the ${ }^{13} \mathrm{C}$ solid-state NMR and ATR-IR data, the pyr-GCMS chromatograms of the three different alkali-treated humins proved to be very similar (not shown).

The combination of different analytical tools and spectroscopic techniques now allows us to identify the chemical changes that occur in the humin samples during alkaline pretreatment. Elemental analysis indicated an increase in the $\mathrm{H} / \mathrm{C}$ ratio while the $\mathrm{O} / \mathrm{C}$ decreased for all humin samples after alkaline treatment, which indicates the loss of $\mathrm{CO}$ or $\mathrm{CO}_{2}$ and probably water, also leading to a slight decrease in molecular weight. Loss of $\mathrm{C}$ and $\mathrm{O}$ without a net decrease of $\mathrm{H}$ could also indicate net decarboxylation, which is unlikely, however, as the ATR-IR and ${ }^{13} \mathrm{C}$ solid-state NMR spectra of alkali-treated humins point at carboxylic acid formation instead. The formation of these acids could be explained by a Cannizzarolike reaction where the hydroxide ion reacts with an aromatic aldehyde leading to the formation of acids.

Both the ATR-IR spectra as well as the ${ }^{13} \mathrm{C}$ solid-state NMR spectra indicate a change in the molecular structure of humins from generally furanic to predominantly arene-rich upon alkaline pretreatment. A clear signal from conjugated aromatic systems was observed in the ${ }^{13} \mathrm{C}$ solid-state NMR spectra of alkali-treated humins; typical signals for oxygen-containing aromatic rings are still observed, though. These could be substituted furanic groups, which is not unexpected given the structure of the parent humins. The formation of a network containing benzofuran and furan rings fused with larger (polycyclic) aromatic structures is more plausible, however, given the overall aromatization of the sample. An overview of the functional groups and structural motifs likely to be present in alkali-treated humins is given in Table 4 together with an estimation of their abundance. The formation of aromatic, conjugated systems was observed before for the gasification of humins, ${ }^{7}$ upon pyrolysis of carbohydrate-derived functional materials ${ }^{29,39}$ and in furanic resins. ${ }^{28}$ The aromatization of the sample and conversion of the furanic structures to more arenic/ 


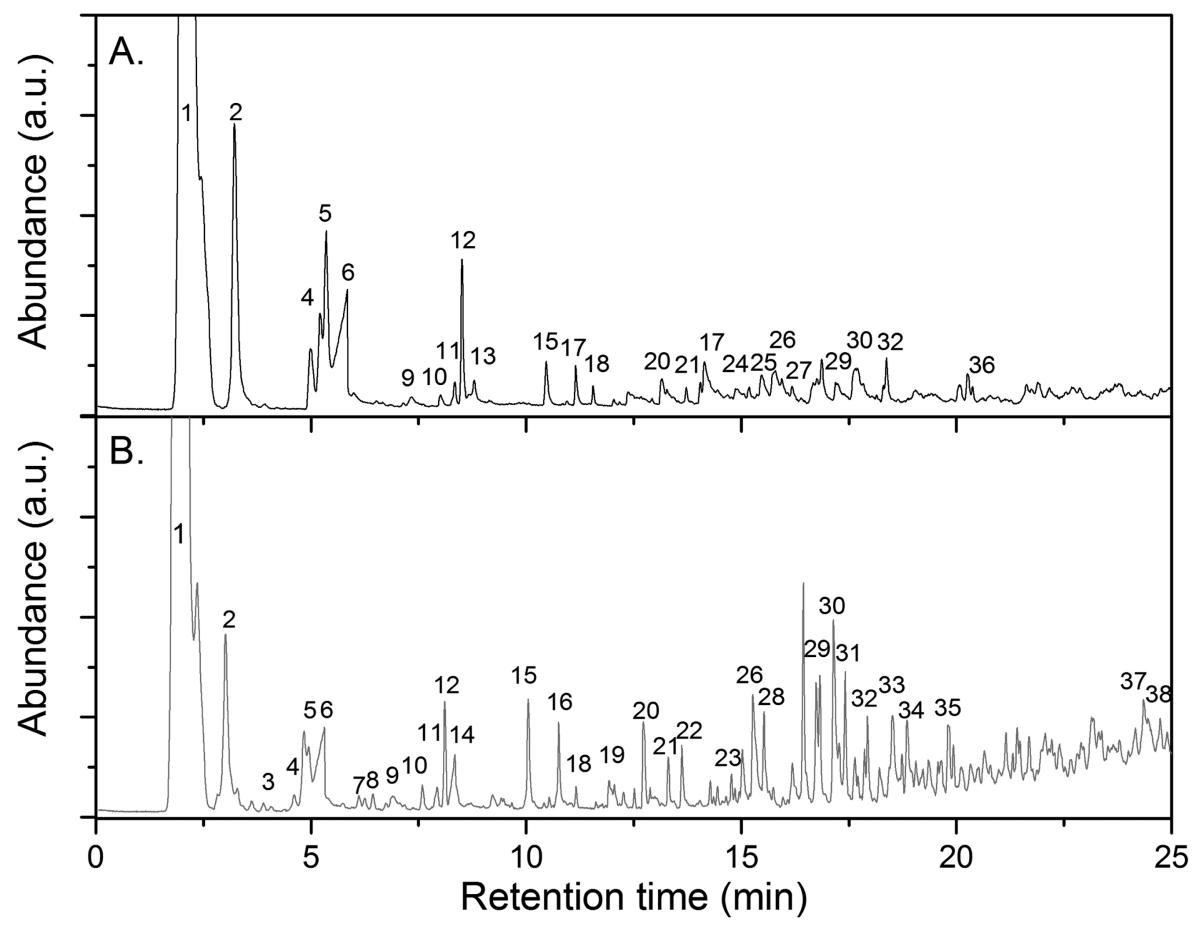

Figure 10. Pyr-GC-MS chromatograms and peak assignments of glucose-derived humins (A) and alkali-treated humins (B).

Table 4. Functional Groups and Molecular Structures Present in Alkali-Treated Humins Including Assignment of the Signals in the Solid-State NMR Spectra (in ppm)

\begin{tabular}{|c|c|c|c|c|c|}
\hline $\begin{array}{l}\text { Functional } \\
\text { group }\end{array}$ & $\begin{array}{l}\text { Chemical } \\
\text { structure }\end{array}$ & $\begin{array}{l}\text { Relative } \\
\text { abundance }\end{array}$ & \begin{tabular}{|l|} 
Functional \\
group
\end{tabular} & $\begin{array}{l}\text { Chemical } \\
\text { structure }\end{array}$ & $\begin{array}{l}\text { Relative } \\
\text { abundance }\end{array}$ \\
\hline $\begin{array}{l}\text { Carboxylic } \\
\text { acids }^{44}\end{array}$ & $\mathrm{R} \underbrace{\mathrm{O}}_{160-180}$ & High & $\begin{array}{l}\text { Furans } \\
\text { Benzofurans } \\
13,28,33\end{array}$ & 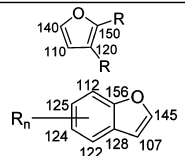 & Low \\
\hline Alkanes $^{44}$ & $\overbrace{15}^{20} \underbrace{40}_{30}$ & High & $\begin{array}{l}\text { Furan ring- } \\
\text { opening } \\
\text { products } \\
45,46\end{array}$ & $\mathrm{I}_{\mathrm{R}}$ & Low \\
\hline $\begin{array}{l}\text { Polycyclic } \\
\text { aromatic }^{\text {sheets }}{ }^{34}\end{array}$ & (130 & High & Ketones $^{44}$ & 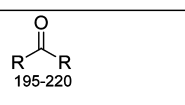 & Low \\
\hline Aldehydes $^{36,44}$ & 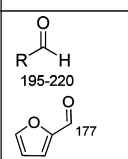 & Low & Phenols $^{37}$ & & Low \\
\hline Alkenes $^{44}$ & ${ }_{100-150}^{R} \widehat{C}_{R}$ & Low & $4 H$-pyrones ${ }^{35,48}$ & & Low \\
\hline Benzene $^{47}$ & $\frac{1}{129.5} R_{n}$ & Low & $\begin{array}{l}\text { Alcohols } \\
\text { Ethers } \\
\text { Acetals } 44\end{array}$ & 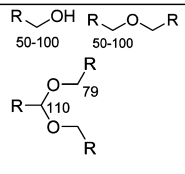 & Very low \\
\hline
\end{tabular}

phenolic ones is furthermore confirmed by the Pyr-GC-MS measurements. At the same time, both the IR and ${ }^{13} \mathrm{C} N M R$ spectra of the alkali-treated humins still show strong signals from aliphatic carbon. Both the IR and NMR spectra point at changes in the aliphatic linkers originally present in the humins, showing that these groups are not left unchanged during the 
formation of the poly-aromatic structures. Alternatively, new aliphatic groups could be formed by Diels-Alder reactions between furanic rings and dienophiles. Further dehydration of the Diels-Alder product could in turn lead to the formation of benzofuran or arene rings. ${ }^{40,41}$ Another possible pathway is based-catalyzed ring-opening, which leads to the formation of aldehydes as was demonstrated for furan-3,4-dicarbaldehyde in methanol. $^{42}$

The increased solubility of the humins seems a bit counterintuitive, given the more extensive aromatization of the humins upon alkaline treatment; this hydrophobization can nonetheless be offset by the formation of carboxylic acids and the gradual decrease in molecular weight. The latter can be caused by the cleavage of $\mathrm{C}-\mathrm{C}$, e.g., by retro aldol reactions, ${ }^{43}$ and $\mathrm{C}-\mathrm{O}-\mathrm{C}$ bonds, e.g., by hydrolysis of ethers and acetals. The first reaction cannot be verified by our experimental data. $\mathrm{C}-\mathrm{O}-\mathrm{C}$ cleavage, however, is supported by the disappearance of signals from aliphatic $\mathrm{C}-\mathrm{O}$ bonds in IR and solid-state NMR spectra after alkaline pretreatment, which indicates that the relatively few ether-like bonds that are present in the humins are hydrolyzed during alkaline pretreatment. The presence of acetals and ethers in the humin's structure has been suggested before by Zarubin et al., ${ }^{9}$ but were not incorporated in our previously presented model of humin molecular structure, as such bonds could not be clearly observed in our data. ${ }^{12}$ Based on the results presented here, the molecular structure of humins can now be somewhat refined by including a small amount of ether or acetal bonds.

\section{CONCLUSIONS}

Alkaline pretreatment proved to be an effective method for the reactive solubilization of humin byproducts. Higher temperatures and prolonged reaction times led to a decrease in the weight-average molecular weight of the dissolved humins as determined by GPC. A hydroxide concentration of $0.5 \mathrm{M}$ was sufficient for the complete solubilization of the humins, whereas additional increases of the base concentration hardly lowered the average molecular weight any further. Fructose- and xylosederived humins proved to be more recalcitrant to the alkaline pretreatment and required higher treatment temperatures for full solubilization. Although this was rather unexpected for the fructose-derived humin, given its structural similarity to the glucose-derived humin, it was not for the more highly crosslinked structure of the xylose-derived humins.

Characterization of the alkali-treated humins using elemental analysis, ATR-IR, solid-state NMR and pyrolysis-GC-MS revealed considerable changes in the humin structure. The more (polycyclic) aromatic structure that is formed is possibly the result of Diels-Alder reactions combined with dehydration reactions; the formation of new aliphatic groups might be the result of ring-opening of the furan, with other furanic rings now most probably being part of benzofurans. Oxygen-containing functional groups change upon alkaline treatment as the amount of ketone groups decreased, while the acid content increased; the latter is linked to the increased solubility of the alkali-treated humins. The reduction in average molecular weight can be explained by cleavage of the $\mathrm{C}-\mathrm{O}-\mathrm{C}$ bonds of which small amounts are present in the parent humin; $\mathrm{C}-\mathrm{C}$ bond cleavage might occur as well, but cannot be evidenced from the data.

Although alkaline pretreatment changes the molecular structure of the humins, the increased solubility in water $\mathrm{pH}$ $\geq 7$ could assist the catalytic valorization of the humin byproducts, allowing better catalyst-substrate interaction, especially when a heterogeneous catalyst is used. Examples of possible valorization routes for the water-soluble humins include, for example, aqueous phase reforming for the production of hydrogen and chemicals or catalytic hydrotreatment using a supported catalyst and molecular hydrogen. The former is well-known for biobased oxygenates 49,50 and was tested for the production of aromatic monomers from lignin, ${ }^{51}$ which indicates that recalcitrant fractions of biomass can be converted by aqueous phase processing. Soluble humin aqueous phase reforming is currently being investigated in our laboratory and will be reported in due course.

\section{AUTHOR INFORMATION}

\section{Corresponding Authors}

*B. M. Weckhuysen. E-mail: b.m.weckhuysen@uu.nl.

*P. C. A. Bruijnincx. E-mail: p.c.a.bruijnincx@uu.nl.

\section{Notes}

The authors declare no competing financial interest.

\section{ACKNOWLEDGMENTS}

This research has been performed within the framework of the CatchBio program. The authors gratefully acknowledge the support of the Smart Mix Program of the Netherlands Ministry of Economic Affairs and the Netherlands Ministry of Education, Culture and Science. Support of NWO for the "Solid state NMR facility for advanced materials science" in Nijmegen is gratefully acknowledged. We thank Yuehu Wang, Henk van de Bovenkamp and Léon Rohrbach from the University of Groningen for humin preparation, elemental analysis and pyrGC-MS. Jacinta van der Putten and Dr. Richard Gosselink from Wageningen University are thanked for performing the GPC analysis. Dr. Marleen Kerssens from Utrecht University is thanked for taking the photographs shown in Figure 1.

\section{REFERENCES}

(1) Lange, J. P.; van der Heide, E.; van Buijtenen, J.; Price, R. Furfural - A promising platform for lignocellulosic biofuels. ChemSusChem 2012, 5, 150-166.

(2) Lange, J. P.; Price, R.; Ayoub, P. M.; Louis, J.; Petrus, L.; Clarke, L.; Gosselink, H. Valeric biofuels: A platform of cellulosic transportation fuels. Angew. Chem., Int. Ed. 2010, 49, 4479-4483.

(3) Horvat, J.; Klaić, B.; Metelko, B.; Sunjić, V. Mechanism of levulinic acid formation. Tetrahedron Lett. 1985, 26, 2111-2114.

(4) Alonso, D. M.; Bond, J. Q.; Dumesic, J. A. Catalytic conversion of biomass to biofuels. Green Chem. 2010, 12, 1493-1513.

(5) Bartels, E. Über die bildung von huminstoffen aus ketosen durch einwirkung konzentrierter halogenwasserstoffsäuren. Dissertation, Hamburg University, Hamburg, Germany, 1966.

(6) Hayes, D. J.; Ross, J.; Hayes, M. H. B.; Fitzpatrick, S. W.; Ross, P. J.; Hayes, P. M. H. B.; Fitzpatrick, P. S. The biofine process: Production of levulinic acid, furfural and formic acid from lignocellulosic feedstocks. In Biorefineries - Industrial Processes and Products; Kamm, B.; Gruber, P. R.; Kamm, M., Eds.; Wiley: New York, 2006; pp 139-164.

(7) Hoang, T. M. C.; Lefferts, L.; Seshan, K. Valorization of huminbased byproducts from biomass processing - A route to sustainable hydrogen. ChemSusChem 2013, 6, 1651-1658.

(8) Rasrendra, C. B.; Windt, M.; Wang, Y.; Adisasmito, S.; Makertihartha, I. G. B. N.; van Eck, E. R. H.; Meier, D.; Heeres, H. $\mathrm{J}$. Experimental studies on the pyrolysis of humins from the acidcatalysed dehydration of C6-sugars. J. Anal. Appl. Pyrolysis 2013, 104, 299-307. 
(9) Sumerskii, I. V.; Krutov, S. M.; Zarubin, M. Y. Humin-like substances formed under the conditions of industrial hydrolysis of wood. Russ. J. Appl. Chem. 2010, 83, 320-327.

(10) Patil, S. K. R.; Lund, C. R. F. Formation and growth of humins via aldol addition and condensation during acid-catalyzed conversion of HMF. Energy Fuels 2011, 25, 4745-4755.

(11) Patil, S. K. R.; Heltzel, J.; Lund, C. R. F. Comparison of structural features of humins formed catalytically from glucose, fructose, and 5-hydroxymethylfurfuraldehyde. Energy Fuels 2012, 26, 5281-5293.

(12) Van Zandvoort, I.; Wang, Y.; Rasrendra, C. B.; van Eck, E. R. H.; Bruijnincx, P. C. A.; Heeres, H. J.; Weckhuysen, B. M. Formation, molecular structure, and morphology of humins in biomass conversion: Influence of feedstock and processing conditions. ChemSusChem 2013, 6, 1745-1758.

(13) Baccile, N.; Laurent, G.; Babonneau, F.; Fayon, F.; Titirici, M.M.; Antonietti, M. Structural characterization of hydrothermal carbon spheres by advanced solid-state MAS ${ }^{13} \mathrm{C}$ NMR investigations. J. Phys. Chem. C 2009, 113, 9644-9654.

(14) Sevilla, M.; Fuertes, A. B. The production of carbon materials by hydrothermal carbonization of cellulose. Carbon 2009, 47, 2281-2289.

(15) Sevilla, M.; Fuertes, A. B. Chemical and structural properties of carbonaceous products obtained by hydrothermal carbonization of saccharides. Chem.-Eur. J. 2009, 15, 4195-4203.

(16) Song, G.; Novotny, E. H.; Simpson, A. J.; Clapp, C. E.; Hayes, M. H. B.; Solos, E.; Bota, R. J.; Janeiro, R. De; Paul, S. Sequential exhaustive extraction of a Mollisol soil, and characterizations of humic components, including humin, by solid and solution state NMR. Eur. J. Soil Sci. 2008, 59, 505-516.

(17) Neyroud, J.; Schnitzer. The alkaline hydrolysis of humic substances. Geoderma 1975, 13, 171-188.

(18) Jakab, T.; Dubach, P.; Metha, N. C.; Deuel, H. Abbau von huminstoffen III. Abbau mit alkali. Zeitschrift für Pflanzenernährung, Dünung, Bodenkd. 1963, 102, 8-17.

(19) Bourbonniere, R. Characterization of sedimentary humic matter by alkaline hydrolysis. Org. Geochem. 1983, 5, 131-142.

(20) Dimmel, D.; Gellerstedt, G. In Lignin and Lignans Advances in Chemistry; Heitner, C., Dimmel, D. R., Schmidt, J. A., Eds.; Taylor and Francis Group: Boca Raton, FL, U.S.A., 2010; pp 349-391.

(21) Thring, R. W. Alkaline degradation of ALCELL® lignin. Biomass Bioenergy 1994, 7, 125-130.

(22) Toledano, A.; Serrano, L.; Labidi, J. Improving base catalyzed lignin depolymerization by avoiding lignin repolymerization. Fuel 2014, 116, 617-624.

(23) Toledano, A.; Serrano, L.; Labidi, J. Organosolv lignin depolymerization with different base catalysts. J. Chem. Technol. Biotechnol. 2012, 87, 1593-1599.

(24) Schuhmacher, J. P.; Huntjes, F. J.; van Krevelen, D. W. Chemical structure and properties of coal. 26. Studies on artificial coalification. Fuel 1960, 39, 223-234.

(25) Van Krevelen, D. W. Graphical-statistical method for the study of structure and reaction processes of coal. Fuel 1950, 29, 269-284.

(26) Antzutkin, O. N.; Shekar, S. C.; Levitt, M. H. Two-dimensional sideband separation in magic-angle-spinning NMR. J. Magn. Reson. 1995, 115, 7-19.

(27) Vogt, F. G.; Gibson, J. M.; Aurentz, D. J.; Mueller, K. T.; Benesi, A. J. Multiple-rotor-cycle 2D PASS experiments with applications to ${ }^{207} \mathrm{~Pb}$ NMR spectroscopy. J. Magn. Reson. 2000, 143, 153-160.

(28) Burket, C.; Rajagopalan, R.; Marencic, A.; Dronvajjala, K.; Foley, $\mathrm{H}$. Genesis of porosity in polyfurfuryl alcohol derived nanoporous carbon. Carbon 2006, 44, 2957-2963.

(29) Falco, C.; Perez Caballero, F.; Babonneau, F.; Gervais, C.; Laurent, G.; Titirici, M.-M.; Baccile, N. Hydrothermal carbon from biomass: Structural differences between hydrothermal and pyrolyzed carbons via ${ }^{13} \mathrm{C}$ solid state NMR. Langmuir 2011, 27, 14460-14471.

(30) Kolodziejski, W.; Klinowski, J. Kinetics of cross-polarization in solid-state NMR: A guide for chemists. Chem. Rev. 2002, 102, 613628.
(31) Opella, S. J.; Frey, M. H. Selection of nonprotonated carbon resonances in solid-state nuclear magnetic resonance. J. Am. Chem. Soc. 1979, 101, 5854-5856.

(32) Alemany, L. B.; Grant, D. M.; Alger, T. D.; Pugmire, R. J. Cross polarization and magic angle sample spinning NMR spectra of model organic compounds. 3. Effect of the carbon-13-proton dipolar interaction on cross polarization and carbon-proton dephasing. J. Am. Chem. Soc. 1983, 105, 6697-6704.

(33) Okuyama, T.; Fueno, T. Substituent effects in the benzofuran system. I. Proton and carbon-13 chemical shifts. Bull. Chem. Soc. Jpn. 1974, 47, 1263-1266.

(34) Hansen, P. E. ${ }^{13} \mathrm{C}$ NMR of polycyclic aromatic compounds. A review. Org. Magn. Reson. 1979, 12, 109-142.

(35) Hobuß, D.; Laschat, S.; Baro, A. Concise two-step synthesis of $\gamma$ pyrone from acetone. Synlett 2005, 123-124.

(36) Fringuelli, F.; Gronowitz, S.; Hörnfeldt, A.-B.; Johnson, I.; Taticchi, A.; Mannervik, B. Nuclear magnetic resonance of aromatic heterocyclics. VIII. A comparative study of ${ }^{1} \mathrm{H}$ and ${ }^{13} \mathrm{C}$ spectra of some 2-substituted furans, thiophenes, selenophenes and tellurophenes. Acta Chem. Scand., Ser. B 1974, 28, 175-184.

(37) Sinha, B. R.; O'Connor, D.; Blum, F. D. Characterization of substituted phenol-formaldehyde resins using solid-state carbon-13 NMR. J. Appl. Polym. Sci. 1989, 38, 163-171.

(38) Gomes, M.; Gandini, A. Synthesis and characterization of poly (2,5-furan dicarboxylate)s based on a variety of diols. J. Polym. Sci., Part A: Polym. Chem. 2011, 49, 3759-3768.

(39) Johnson, R. L.; Anderson, J. M.; Shanks, B. H.; Fang, X.; Hong, M.; Schmidt-Rohr, K. Spectrally edited $2 \mathrm{D}{ }^{13} \mathrm{C}-{ }^{13} \mathrm{C}$ NMR spectra without diagonal ridge for characterizing ${ }^{13} \mathrm{C}$-enriched low-temperature carbon materials. J. Magn. Reson. 2013, 234, 112-124.

(40) Shiramizu, M.; Toste, F. D. On the Diels-Alder approach to solely biomass-derived polyethylene terephthalate (PET): Conversion of 2,5-dimethylfuran and acrolein into p-xylene. Chem.-Eur. J. 2011, $17,12452-12457$.

(41) Cheng, Y.-T.; Huber, G. W. Chemistry of furan conversion into aromatics and olefins over H-ZSM-5: A model biomass conversion reaction. ACS Catal. 2011, 1, 611-628.

(42) Trofimenko, S. 1,1,2,2-Ethanetetracarboxyaldehyde by the opening of a furan ring with hydroxide ion. J. Am. Chem. Soc. 1963, $85,1357$.

(43) Gierer, J. Chemistry of delignification. Wood Sci. Technol. 1985, 19, 289-312.

(44) Balci, M. Basic ${ }^{1} H$-and ${ }^{13} C-N M R$ Spectroscopy, $1^{\text {st }}$ ed.; Elsevier: Amsterdam, Netherlands, 2005.

(45) Asta, C.; Conrad, J.; Mika, S.; Beifuss, U. Laccase-catalyzed stereoselective oxidative ring opening of 2,5-dialkylfurans into 2-ene1,4-diones using air as an oxidant. Green Chem. 2011, 13, 3066-3069.

(46) Clark, J. H.; Cork, D. G.; Gibbs, H. W. The synthesis of 1,4diketones via fluoride-catalysed Michael addition and supportedpermanganate-promoted nef transformation. J. Chem. Soc., Perkin Trans. 1 1983, 2253-2258.

(47) Richards, S. A.; Hollerton, J. C. Essential Practical NMR for Organic Chemistry; John Wiley \& Sons, Ltd: Chichester, U. K., 2010.

(48) Loots, M. J.; Weingarten, L. R.; Levin, R. H. Application of carbon-13 nuclear magnetic resonance spectroscopy to the analysis of charge distribution patterns in unsaturated carbonyl-containing compounds. J. Am. Chem. Soc. 1976, 98, 4571-4577.

(49) Davda, R. R.; Shabaker, J. W.; Huber, G. W.; Cortright, R. D.; Dumesic, J. A. A review of catalytic issues and process conditions for renewable hydrogen and alkanes by aqueous-phase reforming of oxygenated hydrocarbons over supported metal catalysts. Appl. Catal., B 2005, 56, 171-186.

(50) Cortright, R.; Davda, R.; Dumesic, J. Hydrogen from catalytic reforming of biomass-derived hydrocarbons in liquid water. Nature 2002, 418, 964-967.

(51) Zakzeski, J.; Weckhuysen, B. M. Lignin solubilization and aqueous phase reforming for the production of aromatic chemicals and hydrogen. ChemSusChem 2011, 4, 369-378. 
(52) Gosselink, R. J. A.; van Dam, J. E. G.; Scott, E. L.; de Jong, E.; Sanders, J. P. M.; Li, J.; Gellerstedt, G. Fractionation, analysis, and PCA modeling of properties of four technical lignins for prediction of their application potential in binders. Holzforschung 2010, 64, 193200.

(53) Ivchenko, N.; Hughes, C. E.; Levitt, M. H. Application of cogwheel phase cycling to sideband manipulation experiments in solidstate NMR. J. Magn. Reson. 2003, 164, 286-293. 